\title{
A VIDA DE WILLIAM BLAKE: A FORMAÇÃO DE UM GRAVURISTA COM POUCOS RECURSOS
}

\author{
Daniela Schwarcke do Canto \\ Anselmo Peres Alós
}

\begin{abstract}
RESUMO: William Blake nasceu em 1757, e desde muito cedo demonstrou um grande interesse pelas artes. Com poucos recursos financeiros, Blake deparou-se com o problema de como publicar suas obras, chegando assim ao que chamou de "método infernal de impressão", técnica que, segundo Cunningham (1830), "pode ser comparada a poucas coisas". Nesse trabalho, que é parte de uma dissertação de mestrado, analisaremos o Blake gravurista, desde sua primeira formação como aprendiz até seu reconhecimento como o grande artista que foi. Examinaremos autores como Gilchrist, Ackroyd, Tatham, Cunnigham e Smith, entre outros, nas suas impressões da obra de William Blake.
\end{abstract}

Palavras-chave: Blake. Gravurista. Arte. Biografia.

William Blake foi um gravurista, poeta e visionário. Mal compreendido em seu tempo, foi retratado na biografia de Alexander Gilchrist, Life of William Blake: Pictor Ignotus, publicada em 1863. Tal biografia, a primeira sobre tão enigmática criatura, é até hoje considerada uma das mais ricas fontes de pesquisa sobre Blake. Infelizmente, como era costume na época, essa biografia não contém as suas fontes, deixando-nos apenas com hipóteses considerando em quem Gilchrist realmente se apoiou para escrever sua obra. Esse trabalho faz parte de uma dissertação de mestrado, defendida em 2015 na Universidade Federal de Santa Maria, que teve como principal objetivo retratar a figura de Blake transcrita por Gilchrist e, a partir da leitura de textos anteriores a Gilchrist que mencionavam Blake, chegar a hipóteses de quais tenham sido as reais fontes usadas por Gilchrist.

Para formular hipóteses de quais fontes teriam sido usadas por Gilchrist na escrita da biografia, baseamo-nos nas de textos de cinco autores anteriores

\footnotetext{
* Uma primeira versão deste trabalho foi apresentada como comunicação oral no IV Seminário Internacional de Estudos Literários, na URI/Frederico Westphallen (Rio Grande do Sul), em 10 de junho de 2016.
} 
a Gilchrist: Cunningham, J.T. Smith, Malkin, Tatham e Crabb Robinson. Ficou claro, através de estudos comparativos realizados entre a biografia de Gilchrist com esses autores, que Gilchrist teve acesso a eles, sim. Alguns, como é o caso de Crabb Robinson, podemos concluir, através das próprias palavras de Gilchrist na biografia, ele teve a oportunidade de contatar pessoalmente.

As obras deixadas por Blake são fortes e instigantes. Depois de tantos anos da morte de Blake é possível encontrar vários estudos e teses para que se compreenda o trabalho deste artista. Não há, no entanto, uma única fórmula, um único caminho para entender o trabalho de Blake. Ainda temos poucos pesquisadores de Blake no Brasil, e um dos objetivos desta pesquisa é o de tornar esse Pictor Ignotus mais conhecido do público brasileiro. Com esse trabalho, espera-se, mesmo que o relato seja breve, instigar no leitor a vontade conhecer as obras desse gênio louco mais a fundo, levando, quem sabe, a uma nova geração de pesquisadores de Blake no Brasil.

William Blake nasceu em Londres em 28 de novembro de 1757, filho do comerciante James Blake e de Catherine Hermitage. Segundo Peter Ackroyd (1999), em sua biografia de Blake, William teria sido o terceiro filho do casal, visto que o primogênito teria morrido ainda criança, e que mais quatro teriam nascido depois dele: "William Blake foi o terceiro filho em uma família que cresceu de forma constante a incluir ainda mais quarto (o primogênito havia morrido ainda criança)"1 (ACKROYD, 1999, p. 4). Já Gilchrist (1863 [2013]) não menciona este primeiro filho, e diz que William "era filho de James e Catherine Blake, o segundo em uma família de cinco" (GILCHRIST, 1863 [2013], p. 18), no que ele concorda com Cunningham (1830) e Tatham (1828 [1906]); porém, na primeira página, o autor afirma que "Blake o terceiro de sete filhos oriundos do casamento entre James e Catherine" (1863 [2013], p. 1). Já Bentley Jr., na sua biografia de Blake intitulada The Stranger from Paradise, afirma que Catherine Blake, ao chegar à idade de quarenta e dois anos, havia dado à luz seis filhos, e que um havia morrido ainda criança.

A casa da família Blake ficava na Golden Square, número 28, na esquina das ruas Broad e Marshall. A casa de número 28 era "uma edificação antiga, porém grande e substancial” (GILCHRIST, 1863 [2013] p. 19). A loja de James Blake ficava no andar térreo da casa, a sala e cozinha logo acima, e os quartos ocupavam os dois andares superiores.

Como muitas crianças da época, os filhos de James e Catherine foram educados em casa, não chegando a receber uma educação formal, tendo sido alfabetizados pela mãe. Como o filho William desde cedo demonstrava seu gosto pelas artes, os pais, vendo o interesse e o dom do filho, começaram a levar em consideração que talvez o comércio não fosse o futuro ideal para alguém que desenhava no verso dos recibos e que rabiscava o balcão da loja (CUNNINGHAM, 1837, p. 124). Gilchrist não faz uma declaração explícita sobre a educação básica de Blake, porém indica que, depois de receber as

\footnotetext{
${ }^{1}$ Todas as traduções do inglês para o português são dos autores do artigo.
} 
primeiras noções de leitura e escrita, foi praticamente autodidata. "Todo o conhecimento além daquele de leitura e escrita foi adquirido sozinho" (1863 [2013], p. 19). Bentley Jr. lembra que apesar de James Blake fornecer dinheiro ao filho para que pudesse comprar os materiais necessários aos seus estudos, deve ter sido com a mãe, Catherine, que Blake aprendeu a gostar também dos clássicos da literatura (2003, p. 25).

Blake mostrou, desde criança, ser uma pessoa que não aceitava a autoridade; qualquer tipo de regra, de necessidade de submissão, o deixava nervoso, e Tatham (1828 [1906]) explica que o pai, conhecendo o gênio do filho, optou por educá-lo em casa, poupando-lhe dos castigos que certamente fariam parte da sua vida escolar. Segundo Crabb Robinson (1825), Blake não acreditava na educação formal, e, citando Blake, escreve: "De nada serve a educação, é errado. É o grande Pecado. É se alimentar da árvore do conhecimento do Bem e do Mal". Tal opinião provavelmente seria oriunda da tradição dissidente de sua família, o que explicaria também sua crença na existência de ideias inatas, de que tudo que somos, tudo o que temos, nasce conosco. Blake acreditava que somos como um jardim já semeado ou plantado, pois esse mundo seria muito pobre para produzir boas sementes (ACKROYD, 1999, p. 11). O mesmo autor diz que Blake era adepto da autoinstrução e lia muito. Apesar desta prática apresentar algumas desvantagens (ele apresentava alguns problemas de ortografia e gramática nos seus trabalhos ao longo da vida), o possibilitou a desenvolver um modo único de pensar, uma obstinação e uma singularidade pelas quais ficou conhecido pelo resto da sua existência.

De todas as suas leituras na infância como filho de dissidentes, os biógrafos de Blake concordam em dizer que foi a Bíblia a que mais o influenciou e que o acompanhou até o fim da vida. Ackroyd (1999) aponta pelo menos duas imagens nos futuros trabalhos de Blake que ilustram essa influência. A primeira seria a página título de Songs of Innocence, onde aparece uma mulher sentada com um livro aberto no colo e duas crianças ao seu lado, aparentemente lendo o livro, e a segunda, a imagem de um patriarca com os filhos à sua volta, apontando para desenhos bíblicos (essa sendo uma imagem que aparece nas suas ilustrações para o Book of Job). O autor também aponta que ilustrações contidas nas páginas da Bíblia, como cidades em chamas e profetas fazendo gestos amedrontadores, seriam imagens que Blake carregaria em sua mente e expressaria através de suas visões pelo resto da vida.

O menino baixo, porém forte, de um gênio indomável e de uma sensibilidade extraordinária, convenceu os pais que seu futuro estava destinado às artes. O pai, vendo que tamanha imaginação não cabia atrás de um balcão de loja, matriculou-o, em 1767, aos dez anos de idade, na escola de desenho de Henry Pars, conhecida por ser a escola preparatória para a Academia de Pintura e Escultura em St. Martins Lane, a melhor em Londres na época. Por cinco anos Blake estudou arte de uma forma tradicional, com linhas 
claramente definidas. Ele foi treinado como desenhista e estudou o básico da educação artística, e também esculturas em gesso e gravuras de figuras antigas, aprendendo a desenhar olhos, bocas, orelhas e narizes (ACKROYD, 1999, p. 26-27). No seu segundo ano na escola de Pars, Blake pode passar um grande período na galeria do Duque de Richmond em Whitehall, o que possibilitou ao aspirante a pintor a estudar várias esculturas de gesso e também a conviver com os artistas que frequentavam a galeria.

Ainda criança, Blake ganhava algum dinheiro do pai para a aquisição de gravuras para incrementar os seus estudos, e passou a frequentar leilões de arte, assim como também conhecia todas as lojas de gravuras de Londres. Algumas vezes lhe era possível comprar gravuras a três pennies e, mesmo sendo consideradas antiquadas ou pouco interessantes, possibilitaram ao jovem artista iniciar sua coleção de gravuras, que mais tarde, já no final da vida, foi obrigado a vender para se sustentar.

Sobre o período sob os ensinamentos de Pars, Malkin (1806) afirma que foi nessa época que Blake aprendeu a desenhar cabeças, pés e mãos, copiando os moldes em gesso de antiguidades, muitos deles comprados pelo pai, para incrementar os estudos do filho. Malkin (1806) também cita os leilões que Blake já frequentava, com tão pouca idade, sendo chamado pelo leiloeiro Langford, de "meu pequeno connoisseur", muitas vezes facilitando as compras do menino.

Graças à sua constante presença em leilões e lojas de gravuras, Blake teve acesso a muitas obras de arte de diversos artistas. Gilchrist (1863 [2013]) diz que os grandes italianos, como Rafael, Michelangelo, Giulio Romano e os grandes alemães, como Albert Dürer e Martin Hemskerk, entre outros, eram os escolhidos do menino; e estes não eram os artistas que faziam sucesso na época (1863, p. 25). Já na idade adulta, Blake teria escrito "Não posso dizer que Rafael alguma vez me foi escondido desde a minha primeira infância. Eu vi e sabia a diferença entre Rafael e Rubens." (GILCHRIST, 1863 [2013], p. 25), questão também mencionada, usando praticamente as mesmas palavras, por Malkin (1806) e Tatham (1828 [1906]). Segundo Ackroyd (1999), ao mencionar que sabia distinguir Rafael de Rubens, Blake se referia às linhas. Enquanto as linhas em Rafael eram claras e distintas, Rubens usava sombreamentos e tons. E Blake era, ele mesmo, admirador de linhas fortes e bem marcadas, como nas obras de Rafael.

$\mathrm{Na}$ arte da escrita, Blake tinha por influência, entre outros, Spencer e Milton, e, aos doze anos, Blake começa também a escrever, compondo versos irregulares. Aos quatorze anos, ao término de seus estudos com Pars, já mantinha um caderno de anotações onde esboçava seus desenhos e alguns versos, alguns dos quais fariam parte de sua primeira publicação aos vinte e seis anos. Havia chegado a hora de colocar o jovem William, agora no seu décimo quarto ano de vida, como aprendiz, já que ele mesmo havia se negado a entrar para a escola da Royal Academy. Ser aprendiz de um pintor, além de muito oneroso para um pequeno comerciante, não era garantia de sustento ao 
filho. Pensando nisso, James Blake o encaminhou para um gravurista, ofício que não era tão bem-visto como o de pintor, mas que garantiria o pão na mesa até o final da vida do artista.

Gilchrist conta que James Blake levou o filho até William Wynne Ryland, gravurista bastante conhecido na época. Segundo o biógrafo, o menino se negou a ser aprendiz daquele artista, alegando o seguinte ao pai: "eu não gosto do rosto daquele homem: parece que ele vai viver para ser enforcado!" (1863 [2013], p. 29). Ryland era na época o gravurista do rei, amigo de artistas eminentes e parecia ser um homem competente e honesto, que ganhava a confiança de todos que conhecia quase que imediatamente, o que fez com que a declaração do menino soasse um tanto estranha aos ouvidos do pai à época. Mas, doze anos mais tarde, coincidentemente ou não, o gravurista foi condenado por falsificação e condenado à morte na forca.

Aos quatorze anos, Blake tornou-se aprendiz de James Basire, homem de menor reputação, mas correto e detalhista. Na questão da data na qual Blake iniciou seus anos de aprendizagem com Basire, encontramos algumas divergências entre os autores estudados. Malkin (1806) não precisa uma data em que Blake teria começado seu aprendizado com Basire, já Ackroyd (1999) e Bentley Jr. concordam que teria sido em 04 de agosto de 1772, e Gilchrist (1863 [2013]) somente cita o ano de 1771. Todos, no entanto, concordam que Blake teria 14 anos na época. Ackroyd (1999) coloca que, para se tornar aprendiz de Basire, além de uma bonificação de £52, paga por James Blake, o jovem William se comprometia a "não fornicar ou casar, não jogar e não frequentar tavernas ou casas de jogos"; em troca, Basire se comprometia a instruir seu novo aprendiz na "arte e no mistério" de sua profissão, e também alimentá-lo, dar-lhe roupas e protegê-lo pelo período de sete anos (ACROYD, 1999 , p. 33). Basire era um homem de mente aberta, engenhoso, honesto e um mestre generoso. Gilchrist (1863 [2013]) diz que, como desenhista, Blake não havia sido essencialmente influenciado por ninguém, mas como gravurista, certamente havia sofrido a influência de Basire, mesmo que o estilo do mestre tivesse muito pouco em comum com o seu gênio (p. 31).

Blake mudou-se, então, para a residência da família Basire, e provavelmente voltava para casa dos pais apenas aos domingos. James Basire morava em uma casa na rua Great Queen que ele dividia com a esposa e filhos. No andar térreo, ficava o estúdio onde o gravurista e seus aprendizes trabalhavam em torno de doze horas por dia. Gilchrist (1863 [2013]) escreve que Blake dividia o quarto com James Parker, que mais tarde tornou-se seu sócio em uma não muito bem sucedida empresa. Bentley Jr. (2003) diz que Parker teria chegado à casa de Basire um ano após Blake, e que durante este primeiro ano, Blake teria sido seu único aprendiz (p. 39). Assim que Blake foi estudar com Basire, mostrou-se um aprendiz muito meticuloso e aplicado, merecendo de imediato a admiração do mestre:

Como ele era por natureza meticuloso e aplicado, logo 
aprendeu a desenhar primorosamente e a copiar precisamente o que lhe era apresentado, ao gosto de Basire, e recebeu, como se espera de um bom aprendiz, a aprovação e a indulgência do seu mestre (GILCHRIST, 1863 [2013], p. 32).

Ackroyd (1999) afirma que aqui Blake iniciou o caminho que seguiria pelo resto de sua vida. Em 1809, Blake escreveu que, "durante quarenta anos, jamais suspendeu seu trabalho em cobre por um único dia" (p. 34). Blake viveu cercado de potes de ferro para ferver o óleo, panelas para aquecer as placas de cobre, velas de sebo, buris e agulhas, panos de linho, potes para misturar o aqua fortis, panos velhos usados para limpar a tinta das placas e outras ferramentas usadas no ofício escolhido. Segundo Bentley Jr. (2003), era "o organizado caos do trabalho" (p. 34), e complementa dizendo que "Blake conviveu com esse caos pelo resto de sua vida e o transformou em beleza" ( $p$. 34).

Malkin (1806) escreveu que os dois primeiros anos do aprendizado com Basire desenrolaram-se suavemente, até a chegada de dois novos aprendizes, o que "destruiu completamente a harmonia". Bentley Jr. (2003) esclarece que os únicos aprendizes de Basire entre os anos de 1772 e 1779 foram Blake e Parker, e que, portanto, a informação dada por Malkin (1806) de que outros dois aprendizes teriam sido motivo de tensão no estúdio de Basire seria incorreta. Para o autor, tal tensão ocorreu entre Blake e o próprio Parker, que teria tido dificuldades em lidar com o fato de ser mais velho em idade, mas menor em habilidade do que Blake. Segundo Gilchrist (1863 [2013]), Basire teria dito que Blake era muito simples e eles muito astutos. Vendo que a presença dos novos aprendizes poderia de alguma forma prejudicar seu melhor aprendiz, e que as desavenças diárias tiravam sua paz e concentração, Basire decidiu enviar Blake para fazer desenhos das esculturas na Westminister Abbey, oportunidade esta que Blake sempre reconheceu como uma das melhores da sua vida. Para Gilchrist (1863 [2013]), foram estes desenhos que permitiram a Blake não ser um gravurista comum, fugindo das linhas monótonas e regulares.

Tatham (1828 [1906]) menciona que lá, na Westinster Abbey, Blake encontrou um tesouro que soube valorizar, reconhecendo o estilo que ele almejava. Blake desenhava os monumentos da Westminster Abbey com precisão e beleza, sempre atento aos detalhes. Malkin (1806) diz que Blake desenhava os monumentos de todos os ângulos possíveis. As cabeças, ele considerava como retratos, e os ornamentos, ele considerava como "milagres da arte".

Gilchrist (1863 [2013]) diz que, nesta época, era comum ao jovem Blake desfazer-se de seus desenhos. Dos poucos que sobreviveram, um em específico, chamado Edward and Eleanor, chegou a gravar, posteriormente, já no período em que morou em Lambeth (Figura 1). Deste desenho e de outros trabalhos em aquarela do período, Gilchrist (1863 [2013], p.53) diz que possuem pouco da qualidade ou do maneirismo que estamos acostumados a ver em Blake. 


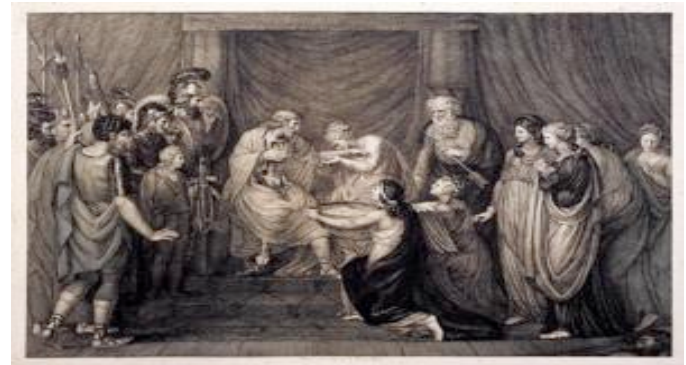

Figura 1: Edward and Eleanor, 1793. Gravura de William Blake. Disponível em: <http://www.blakearchive.org/exist/blake/archive/biography.xq?b=biography\&targ_div=d1>.

Acesso em: 11 de setembro de 2017.

Tatham (1828 [1906]) cita um episódio que pode muito bem representar o nível de concentração e dedicação do rapaz. Na época, os alunos da escola de Westminster podiam circular livremente pela abadia, e, em determinado dia, resolveram interromper o trabalho do jovem aprendiz Blake, que estava absorto em seus desenhos. Para incomodá-lo ainda mais, um dos meninos teria subido no topo de algum monumento para ficar na mesma altura que Blake em seu andaime. Em um ataque de súbita fúria, Blake jogou o menino ao chão, fazendo com que caísse violentamente. $O$ aprendiz de gravurista fez uma reclamação formal ao reitor, o que teria levado à proibição, desde então, dos alunos a circularem pela abadia.

Ackroyd (1999) menciona o fato de que teria sido nesta mesma época que Blake começou a manter um caderno, no qual ele praticava a sua assinatura e também a escrita em reverso, para que, ao ser impresso da placa de cobre, pudesse ser lida normalmente. $O$ autor lembra da importância que esta habilidade teve nos futuros trabalho de Blake, e escreve: "Talvez não seja despropositado que um homem com a habilidade de escrever fluentemente nas duas direções possa se intrigar com os conceitos de 'oposições' e 'contrários'. Ele pode até mesmo considerar a natureza da 'escrita' por si mesma" (Ackroyd, 1999, p. 49). Sobre a arte da escrita em reverso, Bentley Jr. (2003) salienta que:

Blake trabalhava duro para aprender a escrita em reverso, praticando nas páginas em branco de seu Island in the Moon e em outros lugares. Seus próprios trabalhos de Impressões lluminadas são, com claro, todos escritos em reverso, inicialmente com pequenos erros ocasionais. Com o tempo ele se tornou mestre na arte, como pode ser visto em suas inscrições para as Illustrations of the Book of Job (1826) (BENTLEY JR., 2003, p. 37).

Blake passou os meses de verão do ano de 1773 na Westminster Abbey, fazendo os desenhos dos monumentos a serem posteriormente gravados. Nos meses de inverno, Blake ajudava seu mestre a selecionar quais 
desenhos seriam transformados em gravuras, e, em muitos casos, ele mesmo as executava. Tatham (1828 [1906]), cita Malkin ao descrever tais desenhos, e Gilchrist (1863 [2013]), certamente também tendo Malkin (1806) como fonte, descreve o fato da seguinte forma:

Cuidadosos desenhos eram feitos da realeza que por quatro ou cinco séculos repousaram em muda majestade - outrora entre a presença diária de respeitoso sacerdote e massa murmurante, desde então em terrível solidão - ao redor da linda capela do Confessor: a doce austeridade da Rainha Eleanor, a dignidade de Phillipa e a nobre grandeza de Eduardo Terceiro, a graciosa magnificência de Ricardo Segundo e sua rainha. Depois vieram os desenhos da gloriosa efígie de Aymer de Valença, e as primorosas porém mutiladas figuras que contornam seu altar-tumba; desenhos, de fato, todos de tumbas medievais (GILCHRIST, 1863 [2013], p. 3536).

Segundo J. T. Smith (1829), com Basire Blake aprendeu a parte mecânica da arte, copiando com cuidado e atenção cada traço, valendo-lhe a confiança do mestre que frequentemente lhe pedia para desenhar as obras a serem gravadas. Gilchrist (1863) cita que há, pelo menos uma gravura de Blake datada de 1773, apenas dois anos após seu início como aprendiz, já evidenciando, desde tão cedo, seu estilo. Trata-se da gravura Joseph of Arimathea among the Rocks of Albion, onde se pode ler, na parte inferior "Engraved by W Blake 1773 from an old Italian Drawing, Michael Angelo Pinxit" (Figura 2).

Terminado seu período com Basire, Blake começou a trabalhar intensamente como gravurista independente. No princípio, seu trabalho resumia-se basicamente a copiar obras de outros artistas, mas com o decorrer do tempo, começou a trabalhar também em suas próprias obras. O estilo de Blake era, no entanto, peculiar e inquietante, retratando espíritos e corpos, não sendo de fácil compreensão, e, portanto, não sendo de venda fácil.

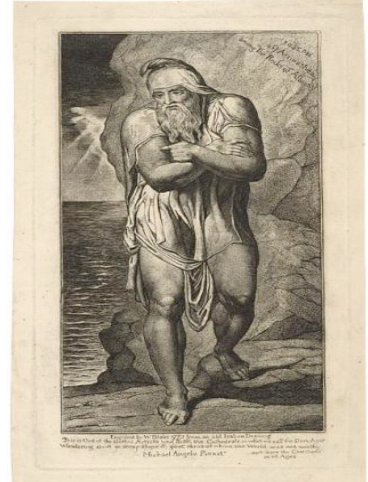

Figura 2: Joseph of Arimathea Among the Rocks of Albion, Gravura de W. Blake, 1773. Disponível em: <http://www.themorgan.org/collection/William-Blakes-World/1\#>.

Acesso em: 16 de junho de 2016. 
Em 1779, Blake, agora com quase vinte e dois anos, começou os estudos na Royal Academy, estudos que ocuparam alguns anos de sua vida, mas que ele abandonou antes de terminar. Os estudos na dita escola eram gratuitos, mas apenas vinte e cinco estudantes eram escolhidos por ano. A escolha era feita através de um desenho que deveria ser enviado aos membros da Academia. Dois meses antes do término do seu período com Basire, Blake enviou um desenho e precisou de uma recomendação de um artista profissional para que pudesse ser aceito na Royal Academy como estudante. A recomendação foi provavelmente de um dos artistas que frequentavam a casa de Basire, ou ainda do próprio Basire ou de Pars, que o conheciam muito bem e admiravam seu trabalho. Bentley Jr. (2003) lembra que, apesar da Royal Academy encorajar a arte da gravura, os gravuristas não eram considerados artistas de verdade, podendo se tornar associados à Royal Academy, mas jamais Acadêmicos Reais (p. 49).

Durante seu tempo na Royal Academy, Blake foi aluno de George Michael Moser, suíço de nascimento, pintor habilidoso na arte decorativa, que Gilchrist (1863 [2013]) descreve como um homem brilhante e educado, certamente um dos favoritos de Sir Joshua Reynolds, presidente da Academia na época. Os alunos também o adoravam, e vários deles, em janeiro de 1783, por ocasião de sua morte, compareceram ao seu enterro e prestaram suas homenagens. Gilchrist (1863 [2013], p. 52) descreve que, apesar de Moser ser admirado pela maioria dos alunos, Blake e ele haviam entrado em discórdia algumas vezes, e lembra da ocasião em que Moser teria dito ao aluno que não deveria estudar as gravuras de Rafael e Michelangelo, chamando-as de "duras, rígidas, secas e inacabadas", mas sim os trabalhos de Le Brun e Rubens. Blake imediatamente objetou, dizendo: "essas coisas que chamas de Acabadas não estão nem Iniciadas; como podem então estar Terminadas? O Homem que não sabe o Início nunca poderá saber o Término da Arte".

A Royal Academy, sob a direção de seu presidente, Sir Joshua Reynolds, tinha como principal objetivo "incutir nos alunos as noções de "beleza ideal' e 'dignidade intelectual" (ACKROYD, 1999, p. 57). O mesmo autor segue dizendo que os ideais da Academia eram muito claros: "Treinar estudantes nos ideais das artes clássicas, incutindo neles um real talento para desenho suas habilidades afins, e promover a ideia de uma escola nacional de pintura histórica" (p. 57). Foi na biblioteca da Royal Academy que Blake teve seus primeiros contatos com ilustrações como o Laocoonte e uma série de gravuras de Michelangelo por Vasari. Para Ackroyd (1999), estes e outros volumes seriam o centro da educação ortodoxa de Blake, e que sua educação anterior, com Pars e Basire fora reforçada pelo estudo minucioso das técnicas do ideal clássico (p. 59). Foi na Royal Academy que Blake teve também contato com modelos vivos, nas aulas de desenho.

Ackroyd (1999) diz que, apesar de Blake não gostar do trabalho com modelos vivos, foi graças a este tipo de observação que ele aprendeu a anatomia da musculatura dos corpos humanos. Figuras humanas ou celestes 
com corpos e musculaturas bem definidas tornaram-se uma marca registrada do artista em muitos dos seus futuros trabalhos. Bentley Jr. (2003) cita que as aulas de anatomia de William Hunter também foram de especial importância para Blake, e que tais aulas contavam, por vezes, com a participação do irmão de Hunter que era cirurgião, ocasiões nas quais eles trabalhavam com cadáveres na aula (p. 50).

$\mathrm{O}$ ano de 1782 foi um ano importante na vida pessoal de Blake. Tatham (1828 [1906]) coloca que, dois anos antes ele havia conhecido e se apaixonado por uma menina tão obstinada quanto rude. Após ser recusado em seu pedido de casamento, Blake adoeceu e foi para o Kew, perto de Richmond, certo de que uma mudança de ares Ihe faria bem. Bentley Jr. (2003), na biografia que escreveu de Blake, diz que provavelmente Tatham se equivocou no local, pois Blake teria sido enviado a Battersea, e não a Kew. Segundo Tatham (1828 [1906]), Blake teria se hospedado na casa dos Boucher, e lá teria conhecido a filha dos donos da casa, Catherine. Cunningham (1830) diz que Catherine era a Kate dos olhos escuros a quem Blake havia se referido em alguns de seus poemas líricos, e diz que o que mais o atraiu em Catherine foi "[...] a alvura de suas mãos, o brilho de seus olhos e sua figura magra e bonita, o que correspondia à sua própria noção de silfos e náiades" (p. 147).

Cunningham (1830) diz que Blake estaria relatando à nova amiga o triste caso de Polly Wood, a menina que o recusou, história à qual ela se demonstrou solidária. Blake então a teria questionado: "Você tem pena de mim?" E a moça imediatamente teria Ihe respondido: "Sim, eu certamente tenho". A resposta do artista foi imediata: "Então eu te amo" (p. 147), e este teria sido o cortejo que levou ao casamento de William e Catherine. Blake ficou impressionado com a ternura da moça, e, pelo que se sabe, Catherine já demonstrava sentir alguma atração por Blake. Tatham (1828 [1906]) conta que, em certa ocasião a mãe havia perguntado à filha se ela estava atraída por alguém, e ela teria respondido que ainda não havia visto tal homem. Mas que, ao entrar na sala onde se encontrava o jovem Blake, ela imediatamente teria reconhecido seu grande amor. Blake então foi embora, com a promessa de voltar assim que conseguisse se estabilizar, e então, casar com Catherine. Um ano depois, cumprindo a promessa, e com a aprovação de seus pais, Blake voltou à casa dos Boucher para pedir a mão de Catherine em casamento.

William Blake e Catherine Boucher se casaram em 18 de agosto de 1782, em uma igreja de Battersea. Gilchrist (1863 [2013]) descreve a igreja recentemente reformada e repleta de imagens e pinturas de símbolos religiosos, muitas de autoria do vigário de gosto duvidoso. Gilchrist questiona: "será que o futuro autor de The Gates of Paradise, Jerusalem e as Ilustrações para o Livro de Jó se ajoelhou sob esses troféus de arte religiosa" (1863 [2013], p. 69). Tatham (1828 [1906]) curiosamente descreve apenas o noivo no dia do casamento, dizendo que, apesar de não ser um homem bonito, ele deveria ter um semblante nobre, cheio de expressão e animação: 
Mesmo não sendo um homem bonito, ele deveria ter um semblante nobre, cheio de expressão e animação; seu cabelo era castanho claro, e tinha um cacheado exuberante; seus cachos, ao invés de cair, ficava em pé como ondas de chama e pareciam, à distância, como radiações, que com seus olhos fogosos e testa larga, sua fisionomia digna e alegre, devem têlo feito parecer verdadeiramente atraente (TATHAM, 1828 [1906], p. 18).

Cunningham (1830) diz que Catherine foi "feita sob medida" para Blake. Ele descreve a esposa de William Blake da seguinte forma:

Ela parecia ter sido feita de propósito para Blake: - ela acreditava que ele era o maior gênio da terra; ela acreditava nos seus versos - ela acreditava nos seus desenhos; e aos voos mais loucos de sua imaginação ela se ajoelhava e era uma adoradora. Ela deixava a casa em ordem, preparava a sua comida, aprendeu a pensar como ele pensava, e, satisfazendoo nos seus absurdos inofensivos, tornou-se ossos de seus ossos, carne de sua carne (CUNNINGHAM, 1830, p. 129).

Ainda segundo Cunningham (1830), ela aprendeu a viver com o pouco que o marido poderia lhe proporcionar, e a ser feliz assim. Catherine ainda aprendeu a ajudar o marido no seu ofício; ela forjava as impressões de suas placas e as coloria com muito cuidado, e também desenhava no espírito dos desenhos do marido. Cunnigham (1830) diz que, no entanto, os pais de Blake não eram a favor do seu casamento com Catherine, fazendo com que o jovem casal se mudasse para uma casa na rua Green, só voltando à casa da rua Broad após a morte do pai. Gilchrist (1863 [2013]), certamente tendo Cunningham como fonte, cita exatamente a mesma coisa.

Crabb Robinson (1825) fala que a sua impressão ao ver Catherine foi de alguém que parecia feliz e que, aparentemente, fazia Blake feliz também. Coloca que Catherine havia sido formada por Blake; que, se não fosse assim, ela não conseguiria viver com ele. Ackroyd (1999) ainda coloca que Catherine chegou a admitir que por vezes não entendia os escritos do marido, mas que tinha certeza que eles tinham um belo sentido. Durante a sua vida junto à Blake, Catherine sempre foi uma companheira fiel e gentil. Blake a chamava de "minha amada", e, segundo Ackroyd, em quarenta e cinco anos de casamento eles se separaram apenas por um curto período de duas ou três semanas. $O$ autor ainda coloca que eles não tiveram filhos (curiosamente nenhum dos filhos de James e Catherine Blake tiveram filhos), e que talvez as crianças do casamento tivessem sido eles próprios. No entanto, foi uma feliz união, do qual o mundo externo foi excluído (1999, p. 80).

Após o casamento, Blake e Catherine mudam-se para a casa de número 23, na rua Green, em Leicester Fields, curiosamente na mesma quadra em que Sir Joshua Reynolds morava e mantinha a sua galeria. O amigo Flaxman era também agora vizinho do novo casal. Blake continuava seu trabalho como 
gravurista. Gilchrist (1863 [2013]) cita alguns destes trabalhos, e elogia principalmente os desenhos que ilustram $A$ Select Collection of English Songs, de Joseph Ritson, dizendo que os desenhos do primeiro volume, a maioria também gravada por Blake, trazem o sentimento e a concepção blakeana, "tendo os ares de graciosas traduções de suas invenções" (p. 82).

$\mathrm{O}$ ano de 1784 marcou a volta de Blake à Royal Academy, desta vez como expositor. Duas de suas obras, intituladas War unchained by an Angel Fire, Pestilence and Famine following (Figura 3) e A Breach in a City - The Morning after a Battle (Figura 4), foram expostas na "Sala de Desenho e Escultura". Ackroyd (1999) diz que, nestes trabalhos de Blake, pode ser percebida a preocupação dele com a morte, a mortalidade e o apocalipse ( $p$. 93). O mesmo ano também trouxe a morte do pai de Blake, James, enterrado em um domingo, dia 4 de julho, em Bunhill Fields. Com a morte do pai, o irmão de Blake, James, assume os negócios e os cuidados com a mãe e a irmã. Gilchrist (1863 [2013], p. 88) descreve a relação de Blake com o irmão da seguinte forma: "entre este irmão e o artista não existia uma forte simpatia, nem uma união de sentimento ou pontos em comum (mentalmente) de qualquer tipo".

Blake, que estava tendo pouco lucro com seus desenhos e gravuras, voltou então, provavelmente no ano de 1782 (BENTLEY JR., 2003) com a esposa para a rua Broad, e alugou a casa de número 27 , ao lado da casa do irmão, onde começou um negócio com o amigo e também gravurista Parker, que havia conhecido na época em que foi aprendiz de Basire. Lá, a família Blake, agora contando também com o irmão Robert, e a família Parker dividiam a casa e os negócios. Bentley Jr. (2003) afirma que "uma das vantagens da firma Parker \& Blake [...] era que ambos eram gravuristas experientes, e assim podiam fazer eles próprios as gravuras para a loja, sem ter que gastar dinheiro com outros gravuristas" (p. 93).

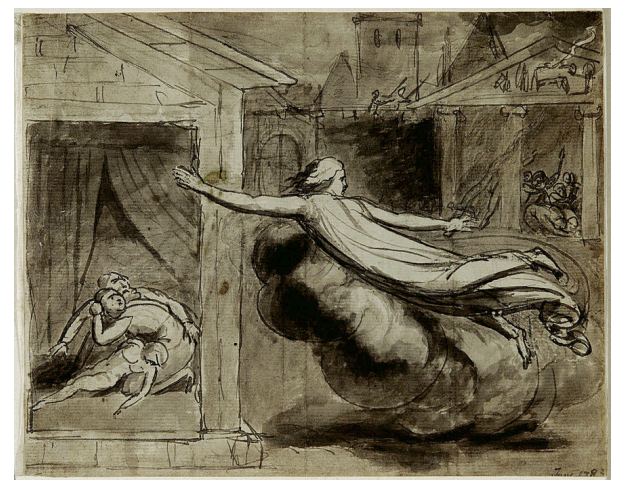

Figura 3: War Unchained by an Angel, Fire, Pestilence and Famine Following. William Blake, 1784.

Disponível em:

<http://www.blakearchive.org//exist/blake/archive/biography.xq?b=biography\&image_mode=true \&targ_div=d2\&targ_pict=BUT.186.r.WD.100>. Acesso em: 16 de julho de 2016. 


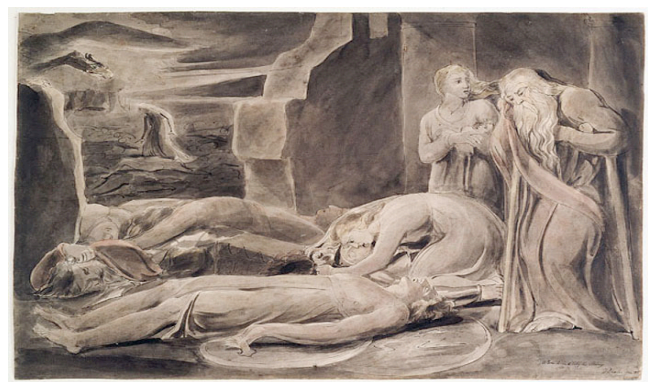

Figura 4: A Breach in a City the Morning after the Battle. William Blake, 1784.

Disponível em: <http://bq.blakearchive.org/img/illustrations/BUT191.1.1.WC.300.jpg>.

Acesso em: 16 de julho de 2016.

Ackroyd (1999) coloca que a loja ficava no andar inferior da casa, e que os andares superiores eram divididos pelas famílias Blake e Parker, prática comum naqueles dias, mas nem por isso fácil. Foi muito provavelmente por este motivo que, um ano depois da abertura do negócio, os Blake mudaram-se para outra casa na rua Poland.

Bentley Jr. (2003, p. 96-97) diz que, mesmo com o talento dos dois sócios, a firma teve problemas financeiros, e que, talvez devido a problemas de ordem pessoal entre os casais ou por conta da falta de dinheiro, clientes e espaço físico, acabou falindo, vindo a dissolver-se em 1785. No âmbito familiar, é a doença de Robert, provavelmente tuberculose, que destrói a alegria do artista. Nos meses em que o irmão esteve doente, Blake e Catherine cuidaram dele com carinho. Gilchrist (1863 [2013]) diz que, nas últimas noites do jovem, Blake não saiu do seu lado, ficando dias sem dormir, e que, ao ver que o irmão havia dado o último suspiro, Blake se entregou a um sono que durou "três dias e três noites". Cunningham (1830) e Smith (1829) falam da morte de Robert e da tristeza que isto causou em Blake e Catherine, o texto de Gilchrist (1863[2013]), no entanto, é bem mais detalhado ao abordar esse assunto. Tatham (1828 [1906]) diz que o irmão mais novo de Blake morreu aos vinte e quatro anos, e Gilchrist concorda com ele ao dizer que Robert morreu no seu vigésimo quinto ano de vida. Já para Ackroyd (1999), a idade de Robert no dia de sua morte era dezenove anos. Robert Blake foi enterrado no dia nove de fevereiro de 1787 em Bunhill Fields, mesmo local em que seu pai havia sido enterrado três anos antes. Bentley Jr. (2003) afirma que Catherine não quis ou não pode acordar o marido de seu sono profundo, o que resultou na falta de Blake ao enterro de seu irmão caçula em 11 de fevereiro de 1787 (p. 98).

Foi na casa da rua Poland que Blake começou a trabalhar no que seria uma das suas obras mais caras, Songs of Innocence and Experience, e que, segundo Cunningham (1830), o consagrariam como um dos gênios do seu tempo. Sobre a composição dessas obras, Cunningham (1830) coloca:

Seu tempo era empregado em esboçar desenhos, gravar placas, escrever canções e compor músicas, com a esposa sempre ao seu lado, encorajando-o em todos os seus empreendimentos. Ao passo que ele desenhava a figura, ele 
pensava na canção que iria acompanhá-la, e a música com a qual o verso deveria ser cantado nascia no mesmo momento (p.130).

Cunningham (1830) ainda lembra que não há exemplos de suas melodias, pois Blake não as anotava (ele não era músico, portanto, provavelmente não sabia escrever partituras), dizendo que, se elas fossem parecidas com os desenhos e os poemas, foram perdidas melodias de grande valor. Songs of Innocence and Experience era composto de cerca de sessenta e cinco ou setenta cenas, apresentando imagens de juventude e de virilidade, com seus problemas e conflitos, contrastando com a vivacidade e felicidade da infância. Cunningham (1830) coloca ainda sobre as Songs:

\begin{abstract}
Todas as cenas são poeticamente acompanhadas, curiosamente entrelaçadas com o grupo e a paisagem, e formando, da harmonia da cor e da beleza dos traços, uma imagem honesta de si mesmo. Estes desenhos são geralmente altamente poéticos, mais aliados, no entanto, ao céu do que à terra - como abstrações espirituais, que indicam um mundo melhor e mais repleto de felicidade do que os mortais conhecem (p. 130).
\end{abstract}

Ao terminar a composição das Songs, em 1788, Blake deparou-se com um grande problema. Como publicar as obras? Pois não possuía recursos próprios para isso, nem fama junto ao público, e também não poderia contar com a ajuda do amigo Flaxman, que se encontrava na Itália na época. Segundo Gilchrist (1863 [2013]), após uma noite de sonhos, Blake acordou e pediu à Catherine que pegasse as economias do casal e comprasse o material necessário para colocar em prática o método de impressão que ele chamaria de "Método Infernal de Impressão":

Tal método, doravante aderido pelo artista para multiplicar suas obras, era bastante original. Consistia em uma espécie de gravura no qual as palavras e os desenhos apareciam em relevo. Os versos eram escritos e os desenhos e ornamentações às margens delineadas no cobre com um líquido impermeável, provavelmente o comum verniz antiácido usado pelos gravadores de seu tempo. Assim, todas as partes brancas ou claras, que ainda lembravam a placa, desapareciam por causa da aquafortis ou de outro ácido, deixando saliente o contorno da letra ou do desenho, como na placa tipográfica tradicional. Destas placas ele conseguia imprimir qualquer tonalidade - amarelo, marrom, azul - cores predominantes nos seus fac-símiles; o vermelho ele usava para a impressão do texto. A página era então colorida à mão, imitando o desenho original, com maior ou menor variedade de detalhes nos tons (GILCHRIST, 1863 [2013], p. 107-108).

Devido a sua excelência técnica, Blake cria o que Cunningham (1830) 
diz que "poder ser comparado a poucas coisas" (p. 133), tamanha sua beleza e originalidade. Gilchrist (1863 [2013]) acrescenta que as aquarelas eram moídas e misturadas por Blake, usando um método que ele havia desenvolvido, no qual ele misturava cola de carpinteiro à tinta (ele dizia que José, o carpinteiro, teria aparecido em uma visão para ele e revelado este segredo). As cores que ele usava eram poucas e simples: índigo, azul cobalto, gamboge (uma espécie de amarelo mostarda), vermillion (vermelho claro), muito preto e raramente azul ultramarino, e nunca prateado (p. 108). Sobre a nova técnica de impressão, Bentley Jr. escreve:

Note que o segredo envolve a adaptação de técnicas e materiais conhecidos (gravura em relevo, verniz) a novas finalidades - e que a primeira finalidade era compor os desenhos diretamente no cobre, o que requeria uma aplicação mecânica do ácido para fazer as placas em relevo que poderiam ser impressas de forma simples e mecânica (BENTLEY JR. 2003, p. 103).

À Sra. Blake cabia a tarefa de retirar as impressões com delicadeza e também de pintá-las, o que o marido a ensinou a fazer com uma perfeição de artista. As placas eram pequenas, medindo um pouco menos de 13 por $8 \mathrm{~cm}$. Isso se dava em função do custo do material, que para os Blake era muito caro. William e Catherine eram os responsáveis por toda a execução da obra, desde a escrita, a ilustração, a impressão e a gravação. Tudo, menos o papel, era confeccionado pelo casal. Gilchrist (1863 [2013]) diz que: "nunca um homem foi tão literalmente o autor de seu próprio livro (p. 109).

Seguiram-se às Songs outros trabalhos que utilizaram o mesmo método de impressão. J. T. Smith (1829) cita The Book of Jerusalem, composto de cem placas, The Marriage of Heaven and Hell, Europe e America, e ainda um outro, chamado The Gates of Paradise. Cunningham (1830) cita ainda outros trabalhos de Blake, em especial Urizen, de 1794, que se tornou conhecido, mas não necessariamente compreendido. Ele coloca que "o espírito que ditou esse estranho trabalho era indubitavelmente um espírito do mal" (p. 134), pois nas vinte e sete lâminas aparecem seres humanos, demoníacos e divinos, todos em situações de dor e sofrimento.

Enquanto os autores anteriores descrevem muito pouco das Songs, Gilchrist (1863 [2013]) fala das Songs of Innocence como arte compósita, sendo impossível separar os poemas das imagens, "tão severa possa parecer sua separação do desenho com o qual é combinado, formando o tear e a trama em uma única tessitura" (p. 109), e compara a sua sonoridade a de vozes angelicais, como se "um mágico estivesse convocando através dos olhos humanos cenas de amor divino" (p. 109). Com uma ingenuidade e espontaneidade dignas de uma criança, as Songs of Innocence tratam do paraíso como visto pelos olhos dos infantes, fazendo com que o leitor se recorde da sua própria infância. Provavelmente como resultado da 
autoinstrução de Blake, é possível encontrar alguns erros gramaticais e ortográficos na obra, mas segundo Gilchrist (1863 [2013]), a melodia suave e a eloquência de ritmo superam esses pormenores. $O$ mesmo autor diz que, ao escrever tais poemas, Blake retornou uma vez mais à infância, demonstrando sentimentos de criança.

Gilchrist (1863 [2013]) lembra a importância da leitura dessas canções em sua integridade, comentário que poderia também incluir a problemática separação que a dimensão textual sofreria de seu meio original, em futuras publicações desta obra. Ackroyd (1999) coloca que as Songs of Innocence não foram, entretanto, um sucesso de vendas. Blake mantinha um pequeno estoque, e, como conservava as placas, poderia imprimir mais se necessário. Mas somente vinte e cinco cópias desta obra foram feitas, o que, segundo Ackroyd, sugere que ela não foi tão bem recebida quanto o autor gostaria que fosse.

Gilchrist (1863 [2013]) também destaca que a pureza e a leveza que aparecem nas Songs of Innocence, não mais apareceriam, nas obras futuras de Blake, e que, ao lançar Songs of Experience, cinco anos mais tarde, Blake já demonstra uma forma mais sombria de escrever, aliada às cores fortes nas gravuras. No ano de 1793, Blake e a esposa se mudam para o Hercules Building, em Lambeth, que era como um condomínio de casas, sendo a dos Blake a de número 13, onde viveriam por sete anos. A casa modesta, com janelas baixas, contava com um pequeno jardim dos fundos, onde crescia uma videira, a qual Blake não podava, e que rapidamente tomou o pátio com grandes folhas e cachos de uvas que jamais amadureciam.

As Songs of Experience foram terminadas em 1794, como complemento das Songs of Innocence. Gilchrist (1863 [2013]) coloca que "fases altamente contrastantes mas harmônicas do pensamento poético são apresentadas pelas duas séries" (p. 181). Dessa segunda série, um poema se destacou e é certamente o poema mais conhecido de Blake até os dias de hoje: "The Tyger" (Figura 5). De todas as lâminas de Songs of Innocence e Songs of Experience, Gilchrist (1863 [2013]) salienta que, no ano de 1863, permaneceram apenas dez, com dezesseis impressões, pois algumas haviam sido gravadas dos dois lados. E diz que o senhor de quem elas foram obtidas contou ter possuído uma série inteira, mas que haviam sido roubadas dele e vendidas a um ferreiro como metal velho (p. 190). 


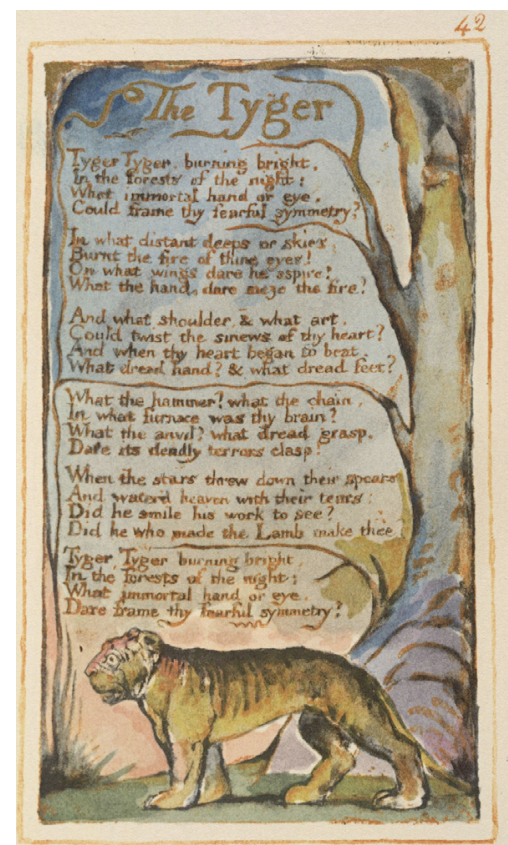

Figura 5: Songs of Innocence and of Experience, "The Tyger" (de William Blake).

Disponível em: <http://static.guim.co.uk/sysimages/Guardian/Pix/pictures/2014/11/18/1416321755537/The-Tyger-written-and-ill-001.jpg> .

Acesso em: 16 de julho de 2016.

No ano de 1795, Blake escreve America, usando o mesmo método de impressão das Songs. Esta obra é composta de dezoito lâminas, ou vinte páginas, contando o frontispício e a página-título. J. T. Smith (1829) descreve a obra, e finaliza dizendo que "os versos não tem rima, e lembram hexâmetros, apesar de não serem exatos; e as expressões são místicas em um grau muito alto". Já sobre Europe, de 1794, J. T. Smith fala que são dezessete lâminas no total e são coloridas imitando a pintura afresco. Ele diz que o frontispício é de beleza incomum e quase se aproxima à grandeza de Rafael ou Michelangelo. Cunningham (1830) afirma ser impossível fazer uma descrição à altura destas obras, que as ilustrações tem sido mais admiradas do que as palavras, e diz que uma das ilustrações mais memoráveis é a da "Grande Serpente do Mar" (Figura 6), na qual uma figura, afundando no mar revolto ao entardecer, produz, com a espuma nas negras ondas, um efeito mágico.

Gilchrist (1863 [2013]) escreve, na biografia The Life of William Blake: Pictor Ignotus, que Europe era um dos trabalhos favoritos de Blake, e que, ao colorir, dedicou a ele mais tempo do que para outras obras. Gilchrist cita que o ato de pintar era muito mais que algo mecânico para Blake; cada cópia pintada era uma nova concepção, um momento de alta inspiração. Cunnigham (1830) dizia que quem quisesse entender Blake tinha que entender primeiramente 0 artista.

O nome de Blake começava a tornar-se conhecido quando foi contratado pelo livreiro Edwards, para ilustrar Night Thoughts, de Young. Apesar do retorno financeiro ser pouco, o reconhecimento vindo a partir deste projeto foi valioso. Cunningham (1830) escreve que tamanho foi o apreço de Flaxman por 
este trabalho, e sua indignação por tão valorosa obra ter recebido tão pouco pagamento, que apresentou o amigo ao poeta Hayley, e este, no ano de 1800, convenceu Blake a mudar-se para Felpham em Sussex, onde ele faria as gravuras para o Life of Cowper, publicado em 1803-1804 e também trabalharia juntamente com Hayley, em outros projetos.

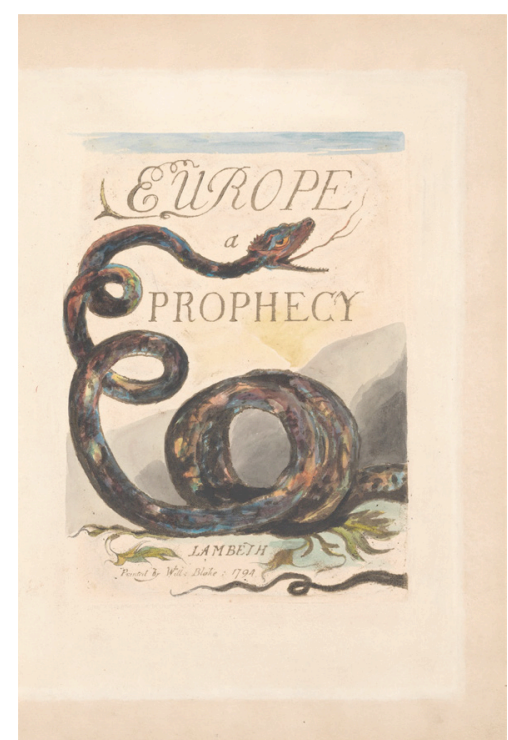

Figura 6: Europe, a Prophecy (William Blake, 1794).

Disponível em: <https://upload.wikimedia.org/wikipedia/commons/a/a3/William_Blake__Europe._A_Prophecy\%2C_Plate_2\%2C_Title_Page_-_Google_Art_Project.jpg >.

Acesso em: 16 de julho de 2016.

Blake muda-se, então, com a esposa e a irmã, para Felpham, onde foi recebido muito amigavelmente por Hayley. Smith (1829) afirma que, ao contrário do que é dito por alguns autores, Blake não ficou hospedado em uma casa cedida por Hayley, mas que pagou vinte libras por ano de aluguel. Gilchrist (1863 [2013], p. 223) também cita o fato de que Blake pagou aluguel pela casa em Felpham, dizendo que este tipo de patrocínio não teria se adequado ao espírito independente do artista. Bentley Jr. (2003) aponta que Blake provavelmente teria se hospedado no The Fox Inn na sua primeira visita à Felpham, e que, nesta visita, teria se encantado com uma cabana à beiramar, pertencente ao mesmo proprietário da hospedaria, tendo negociado seu aluguel no valor de $£ 20$ ao ano (p. 210).

Assim que chegou a Felpham, Blake escreveu ao seu amigo Flaxman, a quem chama de "Prezado Escultor da Eternidade". Na carta, Blake conta como foi a viagem e descreve a cabana, dizendo que o lugar é excelente para os estudos por ser mais espiritual do que Londres, e que está começando, a partir daquele dia, uma nova vida. Durante o período que esteve em Felpham, Blake trabalhava nas gravuras de dia e à noite. Cunningham descreve esse período com as seguintes palavras: "durante o dia ele era um homem de sagacidade e senso, que lidava de maneira prudente com suas gravuras, e conversava de 
uma forma saudável e simpática; à noite, quando já havia terminado as suas tarefas, dava asas à imaginação" (1830, p. 136).

Após um período de três anos em Felpham, Blake retorna à Londres. Tatham (1828 [1906]) diz que Blake teria retornado à Londres porque a grande demanda dos trabalhos com Hayley consumia praticamente todos os seus dias e as suas noites, impossibilitando que se concentrasse em seus próprios trabalhos. Gilchrist (1863 [2013]) coloca que, na bagagem dos três anos em Felpham, Blake carregava com ele, além da amizade que havia conquistado com Hayley, alguns trabalhos inacabados para o Life of Cowper e para o Life of Romney, ambos projetos em parceria com Hayley. Gilchrist (1863 [2013]) diz ainda que Blake havia mencionado, em cartas a um amigo, um longo poema no qual estava trabalhando, descritivo aos três anos de letargia nas margens do oceano. Cunningham (1830) coloca ainda que Blake julgava esse trabalho uma de suas melhores obras, e que, assim, merecia uma apresentação à altura. Blake dirigiu-se ao seu público da seguinte forma, na página 3 de Jerusalem: "após três anos de letargia nas margens do oceano, eu novamente apresento minhas formas gigantes ao público" (1830, p. 138). Gilchrist (1863 [2013]) transcreve toda essa apresentação, que é terminada por Blake da seguinte forma: "leitor, perdoe o que você não aprova \& me ame por esse energético esforço do meu talento" (p. 353). A obra continha cem páginas gravadas, escrita e desenhos, impressas somente em um lado do papel. A maioria das cópias era impressa em preto e branco, algumas com tinta azul, outras com tinta vermelha, e poucas coloridas. O preço para uma cópia colorida era de vinte guinéus. Infelizmente, poucos concordaram com o artista na certeza da magnitude da obra, e muitos a achavam de difícil compreensão. Nem os desenhos, que tanto J. T. Smith (1828) quanto Cunnigham (1830) diziam serem tão ricos quanto os de Michelangelo, fizeram com que a obra fosse um sucesso de vendas.

Nos anos de 1804-1805, Blake havia trabalhado nas ilustrações para The Grave, de Blair, doze ilustrações, ou "invenções" como ele os chamava. Neste trabalho, ele pretendia atuar também como gravurista. Tais gravuras, no entanto, foram vendidas a um gravurista de nome Robert Hartley Cromek, que, segundo Gilchrist (1863 [2013]), tinha pretensões de tornar-se também livreiro, editor e autor. Os desenhos foram vendidos a um baixo preço, mas com a promessa de que Blake faria as gravuras. De fato, Blake chegou a fazer uma ou duas, com o estilo que lhe era próprio, considerado por Cromek como antiquado e muito austero, não sendo o que o público queria, passando, então, o trabalho para o gravurista Louis (Luigi) Schiavonetti, já conhecido de Cromek. Segundo Cunningham (1830), Blake ficou profundamente aborrecido, reclamando ter sido privado de gravar suas próprias ilustrações, e ainda teria dito que Schiavonetti era inapto para o trabalho.

Durante o tempo em que Blake estava trabalhando nos desenhos de The Grave, Cromek havia lhe perguntado qual seria o seu próximo trabalho. Segundo J. T. Smith (1829), Blake havia Ihe mostrado o que seria um desenho 
"a fresco" da obra de Chaucer intitulada The Canterbury Tales, na qual Cromek teria ficado bastante interessado. Smith segue dizendo que pouco tempo depois, Blake ficou sabendo que outro gravurista, conhecido de Blake, de nome Stothard, havia sido contratado por Cromek para fazer um desenho não só sobre o mesmo tema, mas muitíssimo parecido com o que Blake estava trabalhando. Cromek contratou Schiavonetti para gravar a obra, mas este morreu sem a completar, e Smith diz que no mínimo outros três gravuristas trabalharam na placa até sua finalização.

Cunningham (1830) aponta que, se a tranquilidade de Blake ficou abalada com o episódio das ilustrações para The Grave, ele ficou completamente transtornado com o incidente de Canterbury Pilgrims ${ }^{2}$. Crabb Robinson (1825) cita que o trabalho de Stothard era bastante conhecido na época, e o de Blake, pouco conhecido. Gilchrist (1863 [2013]) conta que, como uma resposta à Cromek e Stothard, Blake terminou seu Canterbury Pilgrims com o intuito de mostrá-lo ao público. Determinado a mostrar o seu trabalho, ele organiza sozinho uma exposição de suas obras no primeiro piso da loja do irmão, na rua Broad. A exposição contava com dezesseis "Invenções Poéticas e Históricas", como ele as chamou, onze frescos e sete ilustrações. Com o propósito de justificar seus meios aos homens e aos críticos, Blake criou um Descriptive Catalogue, texto em que interpretava os trabalhos expostos.

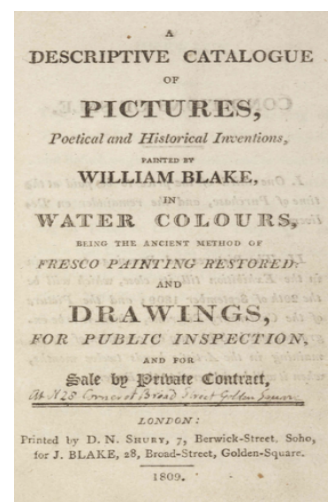

Figura 7: A Descriptive Catalogue of Pictures, Poetical and Historical Inventions. Disponível em: <https://blakearchive.wordpress.com/2014/02/12/tagging-a-descriptivecatalogue/>.

Acesso em: 19 de julho de 2016.

Segundo Gilchrist, poucas pessoas visitaram a exposição, e, destas, muitas foram levadas pela curiosidade de ver o trabalho que estava "rivalizando" com o de Stothard, já famoso. Crabb Robinson visitou esta exposição, e mais tarde escreveu que o catálogo era uma curiosa exposição do estado de espírito do artista (CRABB ROBINSON, 1810). Cunningham (1830), por sua vez, descreve a exposição de Blake na loja do irmão como um

\footnotetext{
${ }^{2}$ Alguns autores tratam a obra como Pilgrimage to Canterbury, outros Canterbury Pilgrims ou ainda Canterbury Pilgrimage. Optamos por usar Canterbury Pilgrims, por ser a forma usada por Alexander Gilchrist em The Life of William Blake: Pictor Ignotus.
} 
fracasso, sendo os seus trabalhos de difícil entendimento para o público:

De desenhos originais esta exposição singular contava com dezesseis - anunciados como 'de natureza espiritual e política' - mas os sentimentos políticos e espirituais de Blake não eram como os das outras pessoas. Uma peça representava 'a forma espiritual de Nelson guinado Leviatã'. Outra, 'a forma espiritual de Sete guiando Mastodonte'. Este, provavelmente confundiu tanto os divinos como os políticos; não há dúvidas que os leigos saíram em espanto. A atração principal era o Canterbury Pilgrimage, não pela sua excelência, mas pelas circunstâncias de sua origem, que já era conhecida na cidade, e também referido no catálogo (CUNNINGHAM, 1830).

No mês de setembro de 1809, Blake inicia a gravura do Canterbury Pilgrims, terminando-a em oito de outubro do mesmo ano, um ano ou dois antes da gravura de Stothard. Gilchrist (1863 [2013]) diz que o trabalho de Blake carece da sedutora graça dos trabalhos de Stothard. O biógrafo cita ainda que há rumores que Blake teria retocado a lâmina de Canterbury Pilgrims, mas não a melhorou.

Cunningham (1830) coloca que, em meio a visões e sendo protagonista de várias histórias contadas até hoje, Blake produziu várias obras de grande valor, sendo uma delas as suas Inventions of the Book of Job (Figura 7). Segundo Cunningham (1830), o bom e velho homem ainda trabalhava com a mesma vontade de sua juventude, e com a habilidade igual ao seu entusiasmo, e o trabalho foi executado em uma pequena sala que Ihe servia de quarto, cozinha e escritório, tendo como única companhia, além das espirituais, a sua fiel esposa Catherine, vivendo do pouco dinheiro que ainda tinham e da bondade de amigos.

Foi o amigo Linnell que contratou Blake para ser o gravurista das suas Inventions of the Book of Job, o que lhe rendia um mínimo para o sustento do casal. J. T. Smith (1829) complementa dizendo que este foi o último trabalho de Blake. Linnell Ihe pagava uma quantia mensal, que, segundo Gilchrist (1863[2013]), seria relativa aos rendimentos da obra. A venda da obra não rendeu lucros, mal cobrindo os gastos, mas Blake recebeu o que the era devido mesmo assim. Gilchrist diz que estas gravuras foram as melhores que Blake já havia feito, creditando esta melhora de Blake como gravurista à sua amizade com Linnell, pois este Ihe havia mostrado os trabalhos de Dürer, Marcantonio e outros, chamando a sua atenção para a forma mais elegante de trabalhar. 


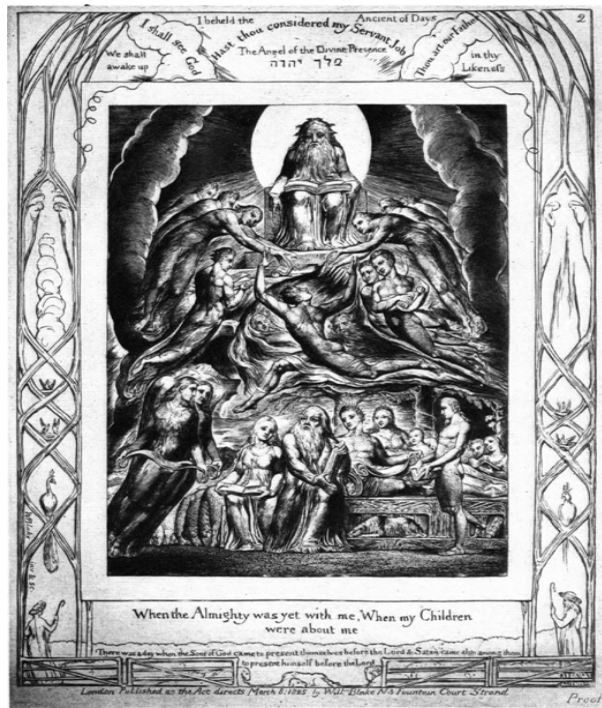

Figura 7: The Inventions of the Book of Job, Lâmina II (William Blake, 1823). Disponível em: <http://lf-oll.s3.amazonaws.com/titles/2155//f1434_figure_003.jpg>.

Acesso em: 16 de julho de 2016.

Cunningham (1830) escreve que "as Canções de Inocência e as Invenções para Jó são os trabalhos mais felizes de Blake, e deveriam estar nos portfólios de todos aqueles que são amantes da natureza e da imaginação" ( $p$. 150-151). Morando em uma casa simples com sua companheira da vida inteira, já no final da vida, Blake dizia não temer a morte, e dizia que seu único pesar era deixar a esposa:

Eu enobreço, ele disse, em morrer, e não tenho outro pesar mas em deixá-la, Katherine; nós vivemos felizes, e vivemos bastante; ficamos sempre juntos, mas logo seremos separados. Porque devo temer a morte? E não a temo. Me esforcei para viver como Cristo manda, e tenho buscado adorar verdadeiramente a Deus - na minha própria casa, quando não era visto pelos homens (CUNNINGHAM, 1830, p. 152).

Blake morreu no dia 12 de agosto de 1828, três meses antes de completar setenta anos, e aparentemente sem sofrer. J. T. Smith (1829) conta que, no dia de sua morte, ele compôs e cantou canções de adoração ao criador. Momentos antes de morrer, ele disse à sua amada que eles não seriam apartados, que ele sempre estaria por perto para dela cuidar.

William Blake foi um gravurista de talento, um pintor com habilidades excepcionais e um escritor de criatividade ímpar. Blake viveu e morreu praticamente na pobreza, e deixou uma obra que muitos consideram de difícil compreensão, mas que traz uma técnica única e inovadora em seu tempo. 


\title{
The Life of William Blake: the formation of an engraver with low resources
}

\begin{abstract}
William Blake was born in 1757 and always demonstrated great interest in arts. With scarce financial resources, Blake faces the problem of how to publish his works, thereby reaching what he called "printing in the infernal method", the technique that, according to Cunningham (1830), "could be compared to few things". In this paper, which is part of a master's degree dissertation, we analyze the engraver Blake, from his first trainings as an engraver to his acknowledgement as a great artist. We will examine authors as Gilchrist, Ackroyd, Tatham, Cunningham and Smith, among others, in their impressions on Blake's work.
\end{abstract}

Keywords: Blake. Engraver. Art. Biography.

\section{REFERÊNCIAS}

ACKROYD, P. Blake. London: Sinclair - Stevenson, 1999.

BENTLEY JR., G. E. The Stranger from Paradise: A Biography of William Blake. New Have and London: Yale University Press, 2003.

BLAIR, R. The Grave. A Poem. London: Mathuen \& Co., 1903.

CUNNINGHAM, A. The lives of the most eminent painters. New York: Harper \& Brothers, 1837. 2 v.

GILCHRIST, A. The life of William Blake: Pictor Ignotus. London: Vintage, 1999.

HAYLEY, W. The life and Letters of William Cowper, Esq. Vol. 1. London: J. Johnson and Co., 1803.

HAYLEY, W. The Life of George Romney, Esq. Chichister: W. Mason, 1809.

MALKIN, B. J. A Father's Memoir of His Child. London: Longman, Hurst, Rees and Orme, 1806.

MILTON, J. O Paraíso Perdido. Tradução Antônio José Lima Leitão. São Paulo: Martin Claret, 2002.

ROBINSON, H.C. The Diary, Letters and Reminiscences of Henry Crabb Robinson. Disponível em:

$<$ https://en.wikisource.org/wiki/William_Blake_(Symons)/Extracts_from_the_Dia 
ry,_Letters,_and_Reminiscences_of_Henry_Crabb_Robinson>. Acesso em: 16 jul. 2016.

SMITH, J. T. Nollekens and His Times. London: Henry Colburn, New Burlington Street, 1829. 2 v.

STUART, J.; REVETT, N. The Antiquities of Athens. London: John Haberkorn, 1762.

THATAM, F. The Letters of William Blake. 1828. Edited by Archibald Russel. London: Mathuen \& Co, 1906.

THE BLAKE ARCHIVE. The William Blake Archive. Disponível em: <http://www. blakearchive.org/blake/>. Acesso em: 19 jul. 2016.

YOUNG, E. Night Thoughts. Edinburgh: J. Nichol, 1853. 